\title{
Sexualidade no território freudiano: uma cartografia moral da diferença sexual
}

\section{Sexuality in Freudian territory: a moral cartography of sexual difference}

\author{
Elizabeth Fátima Teodoro*1 \\ Wilson Camilo Chaves*2
}

Apresenta-se, neste artigo, uma cartografia da diferença sexual, no intuito de refletir sobre as marcas sócio-históricas ocidentais que repercutiram na elaboração da teoria freudiana sobre a sexualidade moderna. Em decorrência dessa reflexão, percebe-se que o discurso referente à diferença natural entre os sexos é recente, motivo pelo qual não devemos tratá-lo com naturalidade. Entende-se que os pressupostos que possibilitaram o nascimento da psicanálise não escapam às tentativas cientificistas de estabelecer a natureza das sexualidades masculina e feminina. Entretanto, ao deslocar o foco da sexualidade do biológico para o psíquico, Freud opera uma leitura que evidencia os rastros de um discurso moral que se mostrava na construção dos laços sociais entre os gêneros, que perpetua, em grande medida, no contemporâneo.

Palavras-chave: Freud, psicanálise e cultura, sexualidade

*1,2 Universidade Federal de São João del Rei - UFSJ (São João del Rei, MG, Brasil). 


\section{Introdução}

Este artigo é resultado de uma investigação teórica de cunho psicanalítico sobre a sexualidade e seus discursos em Freud. Utilizou-se o procedimento de leitura seletiva, reflexiva e interpretativa (Lima \& Mioto, 2007) de escritos freudianos que abordam o assunto e textos de comentadores como Joel Birman, Elisabeth Roudinesco e Maria Rita Kehl, além da obra de Michel Foucault (1988) e Thomas Laqueur (2001) que realizam uma verdadeira arqueologia da temática, permitindo-nos realizar uma contextualização acerca da sexualidade com a qual o mestre de Viena se depara. A leitura desses textos foi enodada pelo método cartográfico de Deleuze e Guatarri (1995), posto que ele possibilitou entrar em um emaranhado de forças que impulsionou a produção de uma forma consistente de interpretação de nosso objeto de pesquisa, com vistas a traçar um mapa dos discursos sobre a sexualidade dos quais Freud parte para desenvolver um "outro" discurso.

Assim, objetiva-se apresentar os pressupostos que possibilitaram o nascimento da psicanálise e cercearam seu desenvolvimento teórico a ponto de se verificar inclusive que Freud "não escapa das tentativas cientificistas de estabelecer a natureza das sexualidades masculina e feminina" (Kehl, 2016, p. 11). O que admite afirmar que o mestre de Viena é um homem do seu tempo, mas que se entenda

Pertence verdadeiramente ao seu tempo [...] aquele que não coincide perfeitamente com ele nem se adequa às suas exigências e é, por isso, nesse sentido, inatual; mas, precisamente por isso, 


\section{HISTÓRIA DA PSICANÁLISE}

exatamente através dessa separação e desse anacronismo, ele é capaz, mais do que outros, de perceber e de apreender o seu tempo. (Agamben, 2014, p. 22)

É nesse contexto que Iannini e Tavares (2018) nos advertem que "Freud não deve ser compreendido ou julgado somente pelos pressupostos aparentes em suas formulações, mas sim por aquilo que seu discurso é capaz de desativar nos dispositivos que herda" (p. 14). Esse é o desafio de ler os textos freudianos levando em consideração seu contexto sócio-histórico sem se perder nele.

\section{Sexualidade e seus impasses no território da cultura}

Refletir sobre a sexualidade não é tarefa fácil por inúmeros motivos, dentre eles, encontra-se a gama variada de dimensões do humano que a envolve, do anatômico e fisiológico passando pelas crenças e fantasias mais íntimas até se instalar nas repressões, tabus e moralizações sociais. "Todas essas variáveis situam-se no ponto de intersecção entre os movimentos próprios à vida e os efeitos particulares das instituições" (Foucault, 1988, p. 27). Assim, a sexualidade parece descortinar a complexa relação existente entre a natureza que persiste no ser humano e o que ele desenvolveu enquanto cultura. É nesse sentido que Nunes (2005) apresenta o campo do sexual como um território híbrido entre o pessoal e o social, constituído de enodamentos confusos que buscam enlaçar o ser individual ao coletivo e vice-versa. Não sem razão ela (a sexualidade) ganhou seu lugar no discurso.

$\mathrm{Na}$ obra de Foucault (2009), o discurso se refere a "um conjunto de regras anônimas, históricas sempre determinadas no tempo-espaço, que definiram em uma dada época e para uma área social, econômica, geográfica, ou linguística dada, as condições de exercício da função enunciativa" (p. 133). Assim, pode-se afirmar que os discursos refletem o funcionamento da sociedade e suas produções subjetivas, como reconhece Lacan (1969-70/1992) ao assegurar que algo da realidade da dinâmica social é passível de ser simbolizado, pois é na condição de funcionar como discurso que a realidade produz efeitos no mundo. Dessa forma, a função de um discurso implicaria a proposição de um laço social, já que eles seriam tecidos e estruturados pela linguagem (Quinet, 2006).

Diante dessa função de laço social, o discurso assume formato de "agenciamento de lugares cujas relações lógicas têm efeitos impositivos para 
toda fala que venha a ser proferida. Vinculação que [...] implica aquele que fala e aquele que se deixa tomar pela implicação dessa fala" (Porge et al., 2015, p. 123). Dessa dinâmica discursiva, interessa-nos a compreensão de que a psicanálise escuta o furo da estrutura presente nesses laços sociais.

Depreende-se com Foucault (1988), a travessia da humanidade pelos discursos mais variados sobre a sexualidade capazes de dotar de sentido e valor condutas, desejos, prazeres, sentimentos, sensações e sonhos. Dispositivo eficaz que as instituições religiosas, judiciárias, pedagógicas e médicas utilizaram para implementar um conjunto de normas que definem como viver em sociedade. Nessa perspectiva, a partir do século XIX, vemos erigir um saber sobre a sexualidade que, ainda hoje, expressa o modo como nos relacionamos com nossa dimensão sexual e a afetação advinda da sexualidade alheia. Esse saber alinhado a um poder permitiu ao discurso científico baseado no conhecimento biológico, médico e criminal produzir efeitos de verdades capazes de legitimar as ditas anormalidades, aberrações e perversões sexuais. Nomeações que não tinham o intuito de assumir um discurso moralizante como anteriormente o religioso possuía. Contudo, tornou-se moralizador por outras vias.

Situação que, na visão de Foucault (1988), serviu somente para "ocultar continuamente o que dele [do sexo] se falava. Poder-se-iam considerar todas as coisas ditas, precauções meticulosas e análises detalhadas, como procedimentos destinados a esquivar a verdade insuportável e excessivamente perigosa sobre o sexo" (p. 52). De que verdade insuportável e perigosa o referido autor falava? Essa questão parece ter habitado a teoria freudiana do seu início ao seu fim e mais além e, muito provavelmente, constitua o motivo pelo qual Freud assentou todo seu edifício teórico por sobre a sexualidade (Roudinesco \& Plon, 1998a), fazendo dela um conceito central para a psicanálise.

Fato é que as investigações freudianas possibilitaram um furo nesse saber científico positivista construído até então, tornando possível o deslocamento de uma perspectiva inteiramente biológica para uma psíquica. Nesse contexto, a sexualidade não pode ser reduzida ao sexo, visto que ela se estende a questões mais amplas que envolvem a psique, razão pela qual Freud utilizou o termo "psicossexualidade" durante parte significativa de sua obra.

Assim, temos uma possível distinção de sexualidade e sexo, de modo que a sexualidade se situa para além do ato sexual e da procriação como indica Freud (1910[1909]/1996c): “É muito possível que me contestem dizendo que [...] emprego a palavra num sentido mais extenso do que estão habituados a entender. Concordo. Mas pode-se perguntar se não têm antes 


\section{HISTÓRIA DA PSICANÁLISE}

utilizado [no sentido que] o limitam ao terreno da procriação" (p. 58). Nas palavras de Foucault (1988), a sexualidade se refere "a verdade do sexo e de seus prazeres [expressos a partir do] conjunto dos efeitos produzidos nos corpos, nos comportamentos, nas relações sociais, por certo dispositivo pertencente a uma tecnologia política complexa" (p. 66).

Para o autor acima mencionado, a sexualidade tem sua origem histórica no seio da burguesia que precisava manter o poder das formas de produção e encontrou na energia sexual a transformação ideal para força de trabalho. Razão pela qual a família nuclear se tornou tão importante no século XIX e o casamento tão fortemente incentivado. Depreende-se então que a sexualidade surge como produto da prática discursiva da scientia sexualis que legitimava a manutenção do controle burguês.

Por outro lado, o sexo apontava para uma cisão, um corte que permitia distinguir fisiologicamente os órgãos sexuais, caracterizando o que se convencionou chamar de macho e fêmea e o ato sexual em si (Senem \& Caramaschi, 2017). É importante evidenciar, porém, como pontua Laqueur (2001) que até o século XVIII, o sexo era compreendido como uma expressão única para homens e mulheres, de modo que os órgãos masculinos, considerados parâmetro, na mulher, estariam invertidos, o que justificava tratá-la como inferior, situação que a colocava na condição de "homem imperfeito".

Esse contexto, então, sugere que havia, nessa época, uma "hierarquia" natural entre os sexos regulada pelo modelo anatômico masculino (Birman, 2016). Com efeito, o discurso referente à "diferença" natural entre os sexos é recente, data de aproximadamente 200 anos, motivo mais que suficiente para não tratarmos com naturalidade esse modelo, do mesmo modo que os discursos normativos que o envolvem.

\section{Entre a hierarquia e a diferença dos sexos: pressupostos freudianos}

Considera-se oportuno realizar um breve recuo que nos permita desnaturalizar o discurso da diferença sexual, marca da modernidade ocidental (Laqueur, 2001; Birman, 2016), visto que uma das principais críticas feitas ao fundador da psicanálise é justamente a perpetuação de uma concepção hierárquica entre os diferentes sexos, ou seja, a utilização de uma lógica binária da sexualidade que termina por prolongar o pensamento patriarcal com a "hipóstase do falogocentrismo" (Iannini \& Tavares, 2018, p. 12). 
Segundo Laqueur (2001), o modelo determinista natural da diferença entre os sexos é bem recente na história da humanidade, posto que se verifica seu aparecimento somente no século XVIII, em decorrência de interesses políticos que descobriram no discurso biológico as bases necessárias para a manutenção do poder na organização social de homens e mulheres. Assim, o ser homem e o ser mulher passaram a ser concebidos a partir de uma concepção inteiramente biológica, marcada por configurações anatômicas e fisiológicas (Birman, 2016). De modo que a diferença sexual ganhou estatuto de categoria ontológica, diferente da visão sociológica que predominou grande parte do século XVII em que "ser homem ou mulher era manter uma posição social, assumir um papel cultural, e não pertencer organicamente a um sexo ou a outro" (Laqueur, 2001, p. 177).

Anterior a esse modelo, vigorou, até o final do século XVIII, a noção do sexo único e da relação hierárquica entre o homem e a mulher. Modelo construído na Antiguidade que teve como principais pensadores o filósofo grego Aristóteles (384-322 a.C.) e o médico grego Cláudio Galeno (130-210 d.C.). O primeiro desenvolveu os alicerces fundamentais da ideia, e o segundo formulou a versão final da teoria.

Em linhas gerais, Aristóteles a partir de sua teoria das quatro causas - material, formal, eficiente e final - propôs a explicação da geração, concebendo a mulher como vetor da causa material e o homem como vetor da causa formal, de modo que "o macho seria [...] o único ser que poderia engendrar um outro. Em contrapartida, a figura da fêmea, enquanto matéria, esperaria passivamente para ser engendrada. A figura do macho seria, pois, atividade, e a da fêmea, passividade" (Birman, 2016, p. 38; grifos do autor).

Ainda que se possa pensar que essa concepção aristotélica dos corpos masculinos e femininos ofereçam sinais de uma oposição sexual, Laqueur (2001) esclarece que para Aristóteles, "homens e mulheres eram classificados conforme seu grau de perfeição metafísica" (p. 17). Portanto, não haveria oposição, mas uma hierarquia da perfeição.

Galeno, por sua vez, complexifica as ideias do filósofo grego ao introduzir a teoria dos humores, na qual "seria a presença e dominância do humor quente no ato da geração que produziria o sexo masculino e sua ausência, o feminino" (Birman, 2016, p. 38; grifo do autor). Em seu entendimento, do mesmo modo que "a humanidade é mais perfeita que o resto dos animais, dentro da humanidade o homem é mais perfeito que a mulher, e a razão dessa perfeição é seu excesso de calor [...] instrumento básico da Natureza" (Laqueur, 2001, p. 44). 


\section{HISTÓRIA DA PSICANÁLISE}

O autor supracitado ainda nos chama a atenção para as explicações anatômicas do médico grego que teriam suas ilustrações insuperáveis até a publicação, em 1543, do livro de anatomia em sete volumes, A estrutura do corpo humano, de André Versalius, médico e anatomista belga. Em suas explicações anatômicas, Galeno desenvolveu um modelo de identidade estrutural dos órgãos reprodutivos do homem e da mulher para demonstrar detalhadamente que as mulheres eram essencialmente homens invertidos, logo, menos perfeitas, visto que a ausência de um humor quente provocaria a retenção interna das estruturas genitais que no homem são visíveis.

Nessa percepção anatômica que pensa a genitália feminina como uma inversão interna, também verifica-se uma noção de atividade e passividade, como pontua Birman (2016): "o polo masculino seria a representação da atividade e da ação, isto é, o que faz protuberância e penetra no espaço exterior, enquanto o feminino seria a representação da passividade e da recepção" (p. 40; grifos do autor). Desse modo, as ilustrações anatômicas apresentavam somente o corpo masculino, visto que ele era considerado o modelo universal e perfeito da anatomia humana, além de ser o único visível.

Esse modelo de sexo único perdurou até o fim do século XVII, entretanto, os primeiros indícios de uma mudança surgem no início do mesmo século com a aparição dos primeiros atlas anatômicos que retratavam as diferenças morfológicas entre os corpos de homens e mulheres. Assim, o modelo da Antiguidade vai cedendo lugar à teoria natural da diferença sexual que se desenvolverá progressivamente ao longo do século XVIII. A partir de então, as marcas biológicas passam a determinar o destino dos sexos (Birman, 2016). Situação extremamente oportuna para se manter a hierarquia entre homens e mulheres, visto que a Revolução Francesa e seu clamor pela igualdade de direitos tornou insustentável uma hierarquia pautada no sexo único (Laqueur, 2001).

Portanto, o cenário jurídico que se organizou a partir da Revolução Francesa não ditou o fim da hierarquização entre os sexos, mas ofereceu um deslocamento para o registro biológico, tornando plausível a justificativa para manter inalterado o poder e o domínio do homem na esfera pública. Forjou-se assim, um novo discurso no qual homens e mulheres possuiriam finalidades e inserções sociais diferentes em decorrência de suas naturezas distintas. Nesses termos, percebe-se a construção de características sociais a partir da condição natural que ditam a inferioridade feminina na nova sociedade civil (Birman, 2016). 
É nesse contexto que o sexo assume a finalidade única de reprodução, o que termina por desatrelar a figura da mulher da sensualidade a fim de se considerar que as faculdades femininas seriam definidas por potencialidades orgânicas de cuidar e acolher o outro próprios da maternidade. Enquanto, ao homem, era atribuída a razão necessária à construção de uma civilização, pensamento que termina por demarcar a cartografia moral da diferença sexual (Birman, 2016).

Por esse viés, nasce, na passagem do século XVIII para o XIX, uma tecnologia do sexo que passa a se organizar em torno da instituição médica (Foucault, 1988) e recebe o nome de sexologia. Cabe ressaltar que essa scientia sexualis, ao se contrapor ao conhecimento religioso, dominante até então, possibilita a mudança "do domínio das perversões morais para o das disfunções sexuais" (Alarcão, Machado \& Giami, 2016, p. 630) e ainda que Freud venha a questionar esses distúrbios, naquele momento, configurou-se como um avanço significativo no discurso sobre a sexualidade. Isso porque "o discurso positivista da medicina mental propõe à burguesia triunfante a moral com que nunca deixou de sonhar: uma moral de segurança modelada pela ciência e não mais pela religião" (Roudinesco, 2008, p. 52).

Vê-se então precipitar, da medicina geral do corpo, a medicina do sexo que "isolou um instinto sexual, suscetível, mesmo sem alteração orgânica, de apresentar anomalias constitutivas, desvios adquiridos, enfermidades ou processos patológicos" (Foucault, 1988, p. 110; grifo do autor), abrindo caminho para que o sexo e questões correlatas como doenças venéreas, alianças matrimoniais e distúrbios sexuais fossem colocados "em posição de responsabilidade biológica com relação à espécie" (pp. 110-111; grifos do autor).

Isso origina não só um projeto médico de controle, mas também político, no qual há uma gestão estatal dos corpos em suas mais variadas relações, de modo que o sexo, dentre outros, torna-se um fator a ser administrado (Foucault, 1988). Gestão que Roudinesco (2008) nomeia de biocracia. Obviamente, esse discurso sexual não se desenvolveu sem uma profunda divergência entre os teóricos da sexologia. Alguns consideravam as perversões sexuais um fenômeno natural; outros, que elas eram adquiridas e, portanto, inerentes da cultura; outros, ainda, acreditavam que se tratavam de patologias hereditárias. Entretanto, todos concordavam que o fundamental consistia em propor algum tipo de tratamento para esses desvios da referida norma (Roudinesco, 2008).

A partir dessa polícia dos corpos, os manuais classificatórios se tornaram importantes guias na distinção entre o normal e o patológico. Assim, Richard 


\section{HISTÓRIA DA PSICANÁLISE}

von Krafft-Ebing (1840-1902), renomado psiquiatra austríaco, considerado um dos fundadores da sexologia com sua publicação da Psychopathia sexualis, em 1886, realizou "uma descrição extraordinária, a partir de casos precisos, de todas as formas possíveis de perversões sexuais: uma espécie de catálogo sofisticado" (Roudinesco \& Plon, 1998b, p. 441) que recorria a uma classificação técnica para designar as anomalias do comportamento humano. É bem verdade que muitas dessas nomenclaturas foram, posteriormente, utilizadas por Freud a ponto de considerarem a psicanálise herdeira desse compêndio.

Nesse sentido, áreas do conhecimento como a psiquiatria e a criminologia encontram, nos "princípios da semiologia (descrição dos símbolos) e da taxonomia (classificação das entidades) [...] o rastreamento, a mensuração, a identificação e o controle de todas as práticas sexuais" (Roudinesco, 2008, p. 53), o respaldo necessário para legitimar um discurso de segregação radical entre uma sexualidade orientada para a procriação (normal), e uma sexualidade pautada no gozo e na esterilidade (patológica, dita perversa).

A partir desse discurso revestido de biológico, Freud (1908/1996b) verifica que a civilização e sua moral sexual provocavam efeitos devastadores à vida sexual dos seres humanos. Portanto, o que antes figurava como discurso natural da diferença entre os sexos se mostra ser, na verdade, um discurso moral dessa diferença.

\section{Cartografia moral da diferença entre os sexos}

Em As estruturas elementares de parentesco, Lévi-Strauss (1982) afirma que a "ausência de regra parece oferecer o critério mais seguro que permita distinguir um processo natural de um processo cultural" (p. 46). Nesse contexto, o sexo poderia ser entendido enquanto natural e as normas que o organizam seriam fruto da cultura. No século XIX, essa moral se fundamentava em uma concepção da sexualidade que tinha por finalidade a reprodução da espécie e tudo que se desviasse desse objetivo era tratado como ameaça à sociedade (Birman, 2016).

Essa ideia coaduna com a teoria da sexualidade freudiana formulada nos "Três ensaios sobre a teoria da sexualidade", na qual a civilização repousa sobre uma renúncia da vida pulsional que jamais é efetuada em sua totalidade (Freud, 1905/1996a). Tamanha renúncia gera consequências que serão teorizadas profundamente, no texto de 1929[1930] "O mal-estar na 
civilização", quando ele constata que a relação conflitual entre a pulsão e a civilização seria de ordem estrutural, isto é, jamais seria ultrapassada (Birman, 2005).

Desse modo, Freud (1905/1996a) evidenciou a existência de uma "relação inversa entre a cultura e o livre desenvolvimento da sexualidade" (p. 229) (natureza humana), uma vez que a civilização impõe regras para controlar grande parte das emoções e vontades dos indivíduos. Por esse viés, verifica-se que a sexualidade, principalmente feminina, tornou-se uma "inimiga" a ser combatida, pois ameaçava o desenvolvimento da civilização.

Esse antagonismo nos leva a questionar: qual o impacto do processo civilizatório sobre a subjetividade e, mais especificamente, sobre a sexualidade? Buscando responder essa questão, o médico vienense descreve três estádios de civilização:

um primeiro em que o instinto sexual pode manifestar-se livremente sem que sejam consideradas as metas de reprodução; um segundo em que tudo do instinto sexual é suprimido, exceto quando serve ao objetivo da reprodução; e um terceiro no qual só a reprodução legítima é admitida como meta sexual. A esse terceiro estádio corresponde a moral sexual 'civilizada' da atualidade. (Freud, 1908/1996b, p. 175; grifos do autor)

A atualidade mencionada pelo fundador da psicanálise se refere ao século XIX e início do século XX, nos quais vemos se estabelecer "os padrões seculares, em que a ideia de Natureza substitui a ideia de Deus" (Kehl, 2016, p. 35). Assim, no terceiro estádio freudiano de civilização, a atividade sexual somente é permitida com vistas à reprodução legítima ou monogâmica, condição que torna a família o centro organizador das relações, seja no espaço privado ou no público.

Dessa forma, Roudinesco (2003) descreve a família moderna como casamentos que se originavam no amor romântico e nos desejos carnais, além de valorizar a divisão do trabalho que passou a definir os papéis sociais do pai, da mãe e dos filhos. Modelo que vigorou do final do século XVIII a meados do século XX e que se desenvolveu por meio de duas grandes ordens, uma biológica (diferença sexual) e outra simbólica (proibição do incesto e outros). Dessa forma, a família possibilita a união de um fato de natureza, inscrito nas leis de reprodução biológica a um fato de cultura, construído pela sociedade. Nessa perspectiva, veremos se consolidar a "moral sexual civilizada" da qual Freud realizou uma leitura original, tendo por base o conflito existente entre a pulsão e a civilização na modernidade (Birman, 2005). 


\section{HISTÓRIA DA PSICANÁLISE}

Para uma configuração precisa desse território da moral sexual civilizada, precisa-se compreender quem foram os burgueses, sua trajetória e as consequências de sua ascensão. Por esse viés, ressalta-se que a chamada burguesia já existia no feudalismo, mas não era uma categoria importante socialmente. No século XVIII, o termo passa a se referir a uma classe responsável pelas atividades de distribuição como o comércio, e não mais à produção. Essa nova classe, burguesia mercantil, consolidou-se no século XIX juntamente com o capitalismo (Sennett, 1999). Nesse percurso, Kehl (2016) nos chama a atenção para "a posição conquistada do burguês contra a posição herdada de outros sujeitos de classes média herdeiros de cargos ou postos da antiga ordem feudal" (p. 32; grifos da autora) que irá delimitar o mapa subjetivo da burguesia dessa época.

Kehl (2016) foi assertiva no uso do termo conquistada para demarcar a condição de subjetividade do burguês, na qual a necessidade extremada de controle de si, dos outros e das transações comerciais ditava o tom das relações. Do mesmo modo que a incerteza de uma posição social e a noção de responsabilidade pelo próprio destino, aliada à instabilidade econômica do período, exigiam a construção de uma imagem capaz de representar essa nova ordem. Nesse sentido, a máscara social se torna um artifício necessário para se transitar pelas contradições da sociedade que exigia a repressão dos afetos e desejos carnais em prol de um maior desenvolvimento.

Com efeito, para Sennett (1999) essa representação nos espaços públicos promoveu o fortalecimento da vida privada, visto que oferecia o descanso dessas demandas sociais. Por consequência, criou-se um antagonismo entre convenção social, própria do espaço público e liberdade que ficou estrito ao domínio privado (Kehl, 2016). Relembrando Arendt (2000), ao caracterizar o privado como o reino da necessidade e o público como o reino da liberdade, verifica-se uma inversão de valores importante para determinar a família como o lugar de intimidade e surgimento do individualismo criado a partir de uma falsa oposição entre o bem comum e o bem pessoal.

Nessa perspectiva, destaca-se que o século XIX foi resultado de uma soma histórica da qual o componente determinante para muitas ações sociais foi, sem dúvida, segundo Hobsbawn (1988), a Revolução Francesa e seus ideais de igualdade, liberdade e fraternidade. Por meio desse contexto revolucionário, toma corpo a discussão sobre sexualidade e emancipação feminina (Iannini \& Tavares, 2018).

Em resposta a esses movimentos feministas, os antifeministas também se expandiram. Gay (2007) cita a promulgação de uma lei, em 1867, que proibia 
pessoas do sexo feminino de participarem de atividades políticas de qualquer espécie na Áustria. Portanto, é importante deixar claro que as premissas da Revolução Francesa não, necessariamente, atingiram as famílias, sobretudo as mulheres e crianças, uma vez que a visão desse período permanece demarcada pelas relações patriarcais.

Deve-se registrar ainda que a construção do ideal de família burguesa se assentava em uma perspectiva amplamente divulgada pela literatura como pode-se perceber nas obras de grandes nomes do romantismo como Johann Wolfgang von Goethe, Vitor Hugo e Charles Dickens que buscavam exaltar as emoções e as inquietações do homem moderno. Nesse sentido, encontra-se na arte literária a reprodução de muitos costumes desse período e a tonalidade da escrita perpassada por um ideal romântico que permeia o casamento no intuito de justificar a manutenção de um status quo social, do qual o homem seria o provedor da casa, cabendo à mulher, por sua vez, a manutenção do ambiente familiar por meio do cuidado do lar, bem como a educação dos filhos.

Percebe-se, desse contexto, a definição dos espaços sociais de pertencimento e seus respectivos poderes e atribuições, tendo como fundamento as virtudes indiscutíveis das diferentes naturezas sexuais. À mulher, foi delegada a função de reprodução própria do espaço privado; ao homem foi atribuída a função da produção inerente ao espaço público. Essa repartição social legitimou ainda o registro dos direitos aos homens e dos costumes às mulheres. Assim, delimita-se um território no qual a diferença sexual "determina a posição da mulher na espécie como procriadora e responsável pela prole" (Kehl, 2016, p. 50), revelando-nos com clareza que um dos grandes objetivos da moral sexual civilizada concernia na manutenção da maternidade, com vistas à reprodução social (Birman, 2016).

A partir dessa dinâmica familiar, Lévi-Strauss (1983) chama a atenção para o fato de que "são as [preocupações] de ordem econômica que desempenham um papel de primeiro plano, pois é sobretudo a divisão do trabalho entre os sexos que torna o casamento indispensável" (p. 84). Dessa maneira, não é difícil perceber que a grande maioria dos casamentos desse período buscavam a manutenção ou ascensão social e conservação ou aquisição de patrimônios. Por esse viés, as mulheres se tornam um importante capital social simbólico ao apresentarem, por meio dos ritos sociais, uma postura que expressa a riqueza de sua família e o prestígio social que possuem nessa sociedade burguesa.

Diante dessa construção, a divisão do trabalho, assim como a definição dos papéis sociais, são sustentadas pelo amor romântico e pela idealização. 


\section{HISTÓRIA DA PSICANÁLISE}

De modo que a maternidade oferecia as qualidades do ideal feminino. Uma boa ilustração dessas atribuições pode ser constatada em vários escritos de Jean-Jacques Rousseau. Um deles, datado de 1762, intitulado "Emílio, ou Da educação" apresentou um modelo de mulher ideal - esposa dedicada, doce e submissa que dominou fortemente o imaginário do século XIX. Contudo, Kehl (2016) chama atenção para o fato de que até hoje é possível escutar, nas clínicas, as ressonâncias desse modelo idealizado de mulher.

Vale dizer, porém, que essa construção imaginária do território doméstico envolto ao amor-paixão e ao ideal de casamento, ao mesmo tempo, propiciou as aventuras fora do matrimônio, tema bastante recorrente em diários cifrados e romances da época (Iannini \& Tavares, 2018). Narrativas que mencionavam histórias de como mocinhas de classe baixa se tornavam válvula de escape para jovens oficiais, bon-vivants dissolutos ou burgueses ricos mimados que buscavam, nas aventuras, prazeres sexuais que as jovens respeitáveis não ofereciam, muitas vezes, nem mesmo após o casamento (Gay, 2007).

Essa situação enseja duas questões importantes que se pode observar a partir dessa noção de moral sexual civilizada que legitima o sexo somente para procriação no casamento. A primeira é como esse discurso reforça as representações sociais da mulher como: santa - aquela mulher dita honesta, devota aos filhos e ao esposo, fiel e casta que tinha sua representação máxima na figura da mãe e da esposa; ou puta — aquela mulher que representava o desvio, a impureza, a imoralidade e a sensualidade, egoísta e infiel, características atribuídas às prostitutas e moças que se entregavam ao sexo antes do casamento sem fins reprodutivos (Birman, 1999).

A segunda questão se refere ao fato de que essa moral sexual civilizada deixou, ao homem moderno, três destinos para sua pulsão sexual: $1^{\circ}$ ) sublimação dos impulsos sexuais que, conforme Freud (1908/1996b), "só pode ser efetuado por uma minoria, e mesmo assim de forma intermitente, sendo mais difícil no período ardente e vigoroso da juventude" (p. 178); $2^{\circ}$ ) válvula de escape por meio de relações extraconjugais; $3^{\circ}$ ) adoecimento, destino percorrido pela grande maioria.

Com efeito, posteriormente, a literatura viria nos mostrar que esses destinos pulsionais também se referiam à mulher moderna que, até então, em sua grande maioria, era representada como uma pessoa frágil, suscetível ao desequilíbrio nervoso decorrente de sua condição biológica menstrual, em suma, uma doente por natureza (Kehl, 2016).

Porém, Gustav Flaubert, em 1856, por meio de seu realismo, começa a ironizar o ideal romântico que descrevia a mulher como figura angelical, fiel e 
satisfeita com sua posição doméstica. Nesse contexto, nasce Madame Bovary, livro que retrata como uma esposa burguesa e frustrada com sua condição buscou nas aventuras extraconjugais a saída para sua insatisfação. Ainda que a história tenha causado um escândalo na época, destaca-se como o final trágico flaubertiano para Emma evidencia o peso das marcas morais do ser mulher na sociedade moderna.

Esboça-se aqui uma diferença fundamental: se o homem era quase estimulado a satisfazer suas pulsões sexuais fora do casamento com mocinhas ingênuas ou prostitutas experientes como a literatura demonstra, à mulher a proibição era severa e extremamente condenável. Posto que a figura maternal deveria ser destituída de sexualidade, mas ao homem era legitimado o direito de se mostrar em sua potencialidade desejante e sua efetiva reprodutividade (Birman, 2016), o que marca uma assimetria entre os sexos.

Isso revela de maneira radical a oposição instituída entre a moral sexual civilizada para o homem e para a mulher. Essas foram as linhas de força que levaram Freud (1908/1996b) a afirmar que ainda que as restrições impostas pela moral sexual civilizada fossem "estendidas à vida sexual masculina [...] as diferenças naturais entre os sexos [impunham] sanções menos severas às transgressões masculinas, tornando mesmo necessário admitir uma moral dupla" (p. 169; grifo do autor).

Nessa leitura da moral sexual civilizada, a demanda sexual desmesurada, ou seja, aquela que transgredia o imperativo da reprodução dentro do contexto do casamento era tratada como anormal, visto que o normal se referia à norma reprodutiva imposta. Delineou-se, assim, um novo campo de anomalias — as perversões sexuais - que eram inimigas do imperativo de reprodução que permitia o controle social (Birman, 2016). Por isso, deveriam ser corrigidas ou eliminadas, em prol das exigências sociais.

Logo, verifica-se que uma das principais consequências da moral sexual civilizada foi a constituição da sexologia, com suas classificações e descrições detalhadas das perversões sexuais (Birman, 2016). Dessa maneira, o discurso biológico-científico passa a ocupar agora posições estratégicas para o mapeamento, sobretudo das mulheres transgressoras que eram classificadas em quatro modalidades principais de desvio moral da sexualidade — prostituição, infanticídio, ninfomania e histeria. As três primeiras correspondiam à escolha do sexo para fins não reprodutivos como destino da sexualidade feminina, e a consequente recusa da maternidade.

Birman (2016) as descrevem da seguinte forma: a prostituta é aquela que utiliza o sexo como forma de vida e se recusa a maternidade e a constituição 


\section{HISTÓRIA DA PSICANÁLISE}

familiar; a ninfomaníaca se caracteriza por excessivos atos sexuais e a infanticida não veria problemas em matar um filho recém-nascido para se livrar do peso da maternidade e permanecer desfrutando de seus encontros sexuais.

A histeria, por outro lado, encontrava-se em um outro registro, uma vez que a mulher histérica era aquela que não aceitava "identificar-se apenas com a maternidade, sendo permeada de fio a pavio pela dimensão erótica" ${ }^{1}$ (Birman, 2016, p. 78). Contudo, enquanto as três primeiras acima descritas se localizavam na "dimensão da passagem ao ato, isto é, de realização direta de seus desejos eróticos e de oposição ativa à maternidade" (p. 78), a histérica se encontrava no registro do imaginário. Isso significa que

A mulher histérica seria aquela que gostaria de ser como a prostituta, a ninfomaníaca e a infanticida, mas que não suportaria ou não aguentaria como as outras passar da imaginação para a ação, isto é, deslocar-se do registro da fantasia para o ato. Isso porque, ficando presa no conflito psíquico entre as demandas opostas do erotismo e da maternidade, não conseguiria jamais se deslocar do registro do imaginário para o do real. Com isso, a mulher histérica adoeceria psiquicamente, presa que ficaria, portanto, ao seu conflito moral imobilizada e mortificada por não exercer todos os seus anseios e desejos. (Birman, 2016, p. 79)

Para Foucault (1988), a histerização do corpo da mulher é resultado de um atravessamento tríplice do processo de integração social. De modo que é preciso que haja uma comunicação entre um corpo social que espera sua reprodução, um corpo familiar que exige a manutenção do espaço doméstico e a vida das crianças que depende de sua responsabilidade biológico-moral. $\mathrm{Na}$ leitura freudiana,

${ }^{1}$ O termo erotismo, para Bataille (1987), corresponde a um mecanismo de ligação entre seres descontínuos que procuram, através da atividade sexual, estabelecer uma relação de continuidade. Mecanismo esse que assume função de subjetivação da atividade sexual, visto que possibilita o desvio pulsional do sexo enquanto ato meramente reprodutivo. Desse modo, percebemos que tal termo não pode ser utilizado como sinônimo de sexualidade, muito menos de atos e impulsos sexuais, pois como afirma Branco (1987, p. 14), "o erotismo deriva de impulsos sexuais, mas é capaz de ultrapassá-los e de se revelar mesmo em contextos onde é grande a repressão à sexualidade, mesmo em casos de extrema sublimação dos impulsos sexuais". 
quanto mais severa houver sido a educação da jovem e mais seriamente ela submeter-se às exigências da civilização, mais receará recorrer a essa saída [infidelidade conjugal]; no conflito entre seus desejos e seu sentimento de dever, mais uma vez se refugiará na neurose. Nada protegerá sua virtude tão eficazmente quanto uma doença. (Freud, 1908/1996b, p. 180)

É nesse contexto que a histeria pode ser pensada como um efeito da moral sexual civilizada do século XIX, ou seja, uma consequência do conflito gerado entre a moral sexual e a sexualidade da mulher que precisava ser contida. Por esse viés, muitos sintomas físicos das mulheres descritos por Sennett (1999) como, anemias, prisões de ventre, fobias, entre outros, parecem compor o espectro das queixas histéricas posteriormente (Kehl, 2016).

Formulações que não, necessariamente, referiam-se ao natural do sexo, mas que utilizava parte de um discurso biológico para sustentar uma moral social preocupada em atender às necessidades econômicas daquele contexto. Assim, entende-se que

A enorme produção teórica entre os séculos XVIII e XIX destinada a fixar a mulher no lugar ao qual sua verdadeira natureza a destinou nos faz desconfiar da naturalidade desse lugar. Recordemos a advertência freudiana de que onde não há desejo não é necessário que exista um tabu. (Kehl, 2016, p. 49; grifo da autora)

As marcas dessa situação serão determinantes para se pensar a sexualidade do próximo século, uma vez que as investigações do mestre vienense são basicamente inseridas nas reminiscências desse período. Por esse viés, "a psicanálise se constituiu como um saber fundado na sexualidade, tendo na histeria seu ponto de inauguração e de incansável indagação" (Birman, 2016, p. 80), visto que Freud deu voz àquelas que foram silenciadas por muitos séculos, mas que na modernidade foram amordaçadas por uma moral sexual civilizada.

\section{Considerações finais}

Neste artigo, buscamos traçar um mapa sucinto dos discursos sobre a sexualidade da Grécia Antiga até Freud, a fim de desnaturalizar a representação de sexualidade centrada na diferença natural entre os sexos. Assim, partindo dos gregos com seu discurso do sexo único que tinha na anatomia masculina seu modelo universal de perfeição, desembarcamos no século 


\section{HISTÓRIA DA PSICANÁLISE}

XVIII com a captura da sexualidade pelo discurso médico-científico de base biológica e determinista que legitimou a distinção sexual por meio da anatomia dos sexos.

É nesse contexto que Freud cria a psicanálise, entende-se, pois, que os pressupostos que possibilitaram esse nascimento não escapam às tentativas cientificistas de estabelecer a natureza das sexualidades masculina e feminina. Questão que pode ser verificada na dedicação teórica do médico de Viena em estabelecer as bases psíquicas das diferenças entre os sexos. O salto teórico que se percebe dos estudos anteriores da sexologia e as investigações freudianas decorrem de um deslocamento que deslizou o foco da sexualidade do puramente biológico, que operava a partir de uma concepção na qual a natureza havia provido as diferenças básicas entre os sexos, para o psíquico, que evidenciava os furos desse discurso, posto que quanto mais se tentava provar que a diferença era natural, mais se percebia o quanto ela era instável e ameaçadora.

Com efeito, Freud opera uma leitura clínica que demonstra as marcas de um discurso moral que se encontrava na origem do sofrimento psíquico de homens e mulheres de sua época. Leitura essa que parece apontar muito mais para uma concepção cultural da sexualidade do que natural, como sugeria o discurso científico da ocasião. Isso porque o fundador da psicanálise ressaltou que há uma linha tênue entre a natureza que se expressa pelo instinto e a natureza humana que se manifesta pela pulsão. Além de mostrar como a segunda se apoia na primeira para nos constituirmos como sujeitos e qual parcela de renúncia dessa pulsão é necessária para nos desenvolvermos culturalmente. Nessa perspectiva, as normas passam a estabelecer os limites entre pulsão e civilização; dito de outra forma, elas apontam para o que deve ser renunciado em prol do progresso civilizatório, a saber, o sexual.

$\mathrm{Na}$ modernidade, o ápice desse desenvolvimento se deu com o que Freud nomeou de moral sexual civilizada que instituiu como normal a prática sexual somente após o casamento e para fins reprodutivos. Situação que terminou por legitimar um discurso natural da diferença entre os sexos, de modo a se definir características, funções e papéis a partir dessas diferenças que culminaram em um pensamento heteronormativo que ignora um olhar positivo da diferença, tentando moldar uma sociedade burguesa utópica constituída de uma única forma de manifestação da sexualidade, desvalorizando-se a diversidade como produção de vida.

Desse modo, o pensamento freudiano permite uma desterritorialização da concepção da anatomia como destino, no ponto em que descortina o conflito entre pulsão e moral sexual civilizada como pano de fundo de um mal-estar psíquico que emerge como real destino da humanidade. Portanto, 
atrelada às marcas anatômicas estaria a moral sexual civilizada produzindo traços psíquicos e delineando seus horizontes irrefutáveis na construção da diferença psíquica entre homens e mulheres.

Agradecimentos: Agradecemos à CAPES pelo financiamento da pesquisa de mestrado "A paixão do feminino: articulações entre masoquismo e fantasia à luz da literatura", da qual se originou o presente artigo e ao Programa de Pós-Graduação em Psicologia da Universidade Federal de São João del Rei - UFSJ pela possibilidade da concretização desse projeto.

\section{Referências}

Agamben, G. (2014). Nudez. Belo Horizonte, MG: Autêntica.

Alarcão, V., Machado, F. L., \& Giami, A. (2016). A construção da sexologia como profissão em Portugal: composição de um grupo profissional e tipos de sexólogos. Ciência \& Saúde Coletiva, 21(2), 629-640. Recuperado em 17 dez. 2018, de: $<$ https://www.scielosp.org/pdf/csc/2016.v21n2/629-640/pt>.

Arendt, H. (2000). A condição humana (10 ed.). Rio de Janeiro, RJ: Forense Universitária.

Bataille, G. (1987). O erotismo. Porto Alegre, RS: L\&PM.

Birman, J. (1999). Cartografias do feminino. São Paulo, SP: Editora 34.

Birman, J. (2005). O mal-estar na modernidade e a psicanálise: a psicanálise à prova do social. Physis: Revista de Saúde Coletiva, 15, 203-224. Recuperado em 20 dez. 2018 de: <http://www.scielo.br/pdf/physis/v15s0/v15s0a10.pdf $>$.

Birman, J. (2016). Gramáticas do erotismo: a feminilidade e suas formas de subjetivação em psicanálise (2a ed.). Rio de Janeiro, RJ: Civilização Brasileira.

Branco, L. C. (1987). O que é erotismo. São Paulo, SP: Brasiliense.

Deleuze, G., \& Guatarri, F. (1995). Mil platôs (vol. 1). São Paulo, SP: Editora 34.

Foucault, M. (1988). História da sexualidade I: A vontade de saber. Rio de Janeiro, RJ: Graal.

Foucault, M. (2009). A arqueologia do saber. Rio de Janeiro, RJ: Forense Universitária.

Freud, S. (1996a). Três ensaios sobre a teoria da sexualidade. In Edição Standard Brasileira das Obras Psicológicas Completas de Sigmund Freud (Trad. James Strachey, vol. 7, pp. 117-231). Rio de Janeiro, RJ: Imago. (Trabalho original publicado em 1905). 


\section{HISTÓRIA DA PSICANÁLISE}

Freud, S. (1996b). Moral sexual ‘civilizada' e doença nervosa moderna. In Edição Standard Brasileira das Obras Psicológicas Completas de Sigmund Freud (Trad. James Strachey, vol. 9, pp. 169-186). Rio de Janeiro, RJ: Imago. (Trabalho original publicado em 1908).

Freud, S. (1996c). Cinco lições de psicanálise. In Edição Standard Brasileira das Obras Psicológicas Completas de Sigmund Freud (Trad. James Strachey, vol. 11, pp. 15-66). Rio de Janeiro, RJ: Imago. (Trabalho original publicado em 1910[1909]).

Gay, P. (2007). Freud: uma vida para o nosso tempo (15 reimp.). São Paulo, SP: Companhia das Letras.

Hobsbawn, E. (1988). A era dos impérios: 1875-1914 (5ª ed.). Rio de Janeiro, RJ: Paz e Terra.

Iannini, G., \& Tavares, P. H. (2018). Sobre amor, sexualidade, feminilidade. In S. Freud, Obras incompletas de Sigmund Freud: Amor, sexualidade, feminilidade (Trad. Pedro Heliodoro Tavares, vol. 7, pp. 7-35). Belo Horizonte, MG: Autêntica.

Kehl, M. R. (2016). Deslocamentos do feminino: a mulher freudiana na passagem para a modernidade (2a ed.). São Paulo, SP: Boitempo.

Lacan, J. (1992). O seminário. Livro 17. O avesso da psicanálise. Rio de Janeiro, RJ: Jorge Zahar. (Trabalho original publicado em 1979-70).

Laqueur, T. (2001). Inventando o sexo: corpo e gênero dos gregos a Freud. Rio de Janeiro, RJ: Relume-Dumará.

Lévi-Strauss, C. (1982). As estruturas elementares do parentesco. Petrópolis, RJ: Vozes.

Lévi-Strauss, C. (1983). A família. In O olhar distanciado (Cap. 3, pp. 69-98). Lisboa, PT: Edições 70.

Lima, T. C. S. de, \& Mioto, R. C. T. (2007). Procedimentos metodológicos na construção do conhecimento científico: a pesquisa bibliográfica. Revista Katálysis, 10(spe), 37-45. https://dx.doi.org/10.1590/S141449802007000300004.

Nunes, C. A. (2005). Desvendando a sexualidade ( $7^{\mathrm{a}}$ ed.). Campinas, SP: Papirus.

Porge, E. et al. (2015). O espaço social na psicanálise. In Manifesto pela psicanálise (Cap. 4, pp. 111-143). Rio de Janeiro, RJ: Civilização Brasileira.

Quinet, A. (2006). Psicose e laço social. Rio de Janeiro, RJ: Jorge Zahar.

Roudinesco, E. (2003). A família em desordem. Rio de Janeiro, RJ: Jorge Zahar.

Roudinesco, E. (2008). A parte obscura de nós mesmos - Uma história dos perversos. Rio de Janeiro, RJ: Jorge Zahar.

Roudinesco, E., \& Plon, M. (1998a). Sexualidade. In Dicionário de psicanálise (pp. 704-705). Rio de Janeiro, RJ: Jorge Zahar.

Roudinesco, E., \& Plon, M. (1998b). Krafft-Ebing, Richard von (1840-1902). In Dicionário de psicanálise (pp. 441). Rio de Janeiro, RJ: Jorge Zahar. 
Roudinesco, E., \& Plon, M. (1998c). Hereditariedade-degenerescência. In Dicionário de psicanálise (pp. 331-332). Rio de Janeiro, RJ: Jorge Zahar.

Senem, C. J. \& Caramaschi, S. (2017, jan./jun.). Concepção de sexo e sexualidade no ocidente: origem, história e atualidade. Barbarói, 49, 166-189. Recuperado em 15 dez. 2018 de: <https://online.unisc.br/seer/index.php/barbaroi/article/view/6420>

Sennett, R. (1999). O declínio do homem público: as tiranias da intimidade. São Paulo, SP: Companhia das Letras, 1999.

Valas, P. (1990). Freud e a perversão. Rio de Janeiro, RJ: Jorge Zahar

\section{Resumos}

(Sexuality in Freudian territory: a moral cartography of sexual difference)

This article maps sexual difference to reflect on Western socio-historical features that influenced Freud's theory on modern sexuality. As a result, we note that the discourse on the natural difference between genders is recent, which is why we should not take it as a matter of course. It is understood that the assumptions that enabled the birth of psychoanalysis do not escape scientific attempts to establish the nature of male and female sexualities. However, by shifting the focus of sexuality from the biological to the psychic, Freud performs a reading that shows the marks of a moral discourse that has shown in the construction of social bonds between genders and still impacts, to a large extent, our contemporary era.

Key words: Freud, psychoanalysis and culture, sexuality.

(La sexualité sur le territoire freudien: une cartographie morale de la différence sexuelle)

Cet article présente une cartographie de la différence sexuelle afin de réfléchir sur les marques socio-historiques occidentales qui ont eu des répercussions sur l'élaboration de la théorie de Freud sur la sexualité moderne. Cette réflexion montre que le discours sur la différence naturelle entre les sexes est récent, raison pour laquelle nous ne devrions pas le considérer comme une évidence. Il est entendu que les hypothèses qui ont donné naissance à la psychanalyse n'échappent pas aux tentatives scientifiques visant à établir la nature des sexualités masculines et féminines. Cependant, en déplaçant le centre de la sexualité du biologique vers le psychique, Freud opère une lecture qui met en évidence les traces d'un discours moral qui s'est manifesté dans la construction de liens sociaux entre les sexes et qui se perpétue en grande partie dans le contemporain.

Mots clés: Freud, psychanalyse et culture, la sexualité 


\section{HISTÓRIA DA PSICANÁLISE}

(Sexualidad en territorio freudiano: una cartografía moral de la diferencia sexual)

Este artículo presenta una cartografia de la diferencia sexual, con el fin de reflexionar sobre las marcas sociohistóricas occidentales que repercutieron en la elaboración de la teoría de Freud sobre la sexualidad moderna. Como resultado de esta reflexión, queda claro que el discurso sobre la diferencia natural entre los sexos es reciente $y$, por lo tanto, no debemos tratarlo de forma natural. Se entiende que las premisas que permitieron el nacimiento del psicoanálisis no escapan a los intentos científicos de establecer la naturaleza de las sexualidades masculina y femenina. Sin embargo, al cambiar el enfoque de la sexualidad, yendo de lo biológico a lo psíquico, Freud realiza una lectura que resalta las marcas de un discurso moral que se mostraba en la construcción de los lazos sociales entre géneros, que se perpetúa, en gran medida, en lo contemporáneo.

Palabras claves: Freud, psicoanálisis y cultura, sexualidad

Citação/Citation: Teodoro, E. F, \& Chaves, W. C. (2020, março). Sexualidade no território freudiano: uma cartografia moral da diferença sexual. Revista Latinoamericana de Psicopatologia Fundamental, 23(1), 99-120. http://dx.doi.org/10.1590/1415-4714.2020v23n1p99.7.

Editora/Editor: Profa. Dra. Ana Maria Rudge

Submetido/Submitted: 27.9.2019/ 9.27.2019 Revisado/Revised: $12.12 .2019 / 12.12 .2019$

Aceito/Acepted: 4.2.2020/2.4.2020

Copyright: (C 2009 Associação Universitária de Pesquisa em Psicopatologia Fundamental/ University Association for Research in Fundamental Psychopathology. Este é um artigo de livre acesso, que permite uso irrestrito, distribuição e reprodução em qualquer meio, desde que o autor e a fonte sejam citados / This is an open-access article, which permits unrestricted use, distribution, and reproduction in any medium, provided the original authors and sources are credited. 
Financiamento/Funding: Este trabalho recebeu apoio da Coordenação de Aperfeiçoamento de Pessoal de Nível Superior - Capes (Brasília, DF, Br) / This work is supported by. Coordenação de Aperfeiçoamento de Pessoal de Nível Superior - Capes (Brasília, DF, Br).

Conflito de interesses/Conflict of interest: Os autores declaram que não há conflito de interesses. / The authors declare that there is no conflict of interest.

\section{Elizabeth FÁtima Teodoro}

Enfermeira graduada pelo Centro Universitário de Formiga - Unifor (Formiga, MG, Br); Pós-graduada em Gestão em Saúde Mental pela Universidade Campos Mendes (Rio de Janeiro, RJ, Br); Graduada em Psicologia pela Universidade do Estado de Minas Gerais (Divinópolis, MG. Br); Mestranda em Psicologia, na linha "Fundamentos teóricos e filosóficos da Psicologia” pela Universidade Federal de São João Del Rei (São João del Rei, MG, Br). Rua Santo Antônio do Monte, 90/401 - Morada Nova

35501-25 Divinópolis, MG, Br

elektraliz@yahoo.com.br

https://orcid.org.0000-0003-0977-7265

\section{Wilson CAmilo Chaves}

Docente da graduação de Psicologia e do Programa de Pós-Graduação em Psicologia PPGPSI/UFSJ (São João del Rei, MG, Br); Doutor em Filosofia pela Universidade Federal de São Carlos - UFSCar (São Carlos, SP, Br); Membro do GT Filosofia e Psicanálise e do GT Filosofia da Religião da Associação Nacional de Pós-graduação em Filosofia - ANPOF.

Praça Dom Helvécio, 74 - Fábricas

36301-160 São João del Rei, MG, Br.

camilo@ufsj.edu.br

https://orcid.org.0000-0003-2368-0080

This is an open-access article, which permits unrestricted use, distribution, and reproduction in any medium for non-commercial purposes provided the original authors and sources are credited. 